\title{
Combination of low-dose glucocorticosteroids and mineralocorticoids as adjunct therapy for adult patients with septic shock: a systematic review and meta-analysis of randomized trials and observational studies
}

Paraschos Archontakis Barakakis, Leonidas Palaiodimos ${ }^{1}$, Derlis Fleitas Sosa, Linda Benes, Perminder Gulani, Daniel Fein ${ }^{1}$ Department of Medicine, Jacobi Medical Center, ${ }^{1}$ Department of Medicine, Montefiore Medical Center, Albert Einstein College of Medicine, Bronx, New York, USA

\begin{tabular}{|c|}
\hline Access this article online \\
\hline Website: www.avicennajmed.com \\
\hline DOI: 10.4103/ajm.AJM_97_19 \\
\hline Quick Response Code: \\
\hline$\square$ \\
\hline$\square$ \\
\hline
\end{tabular}

\section{ABSTRACT}

Background: The role of the combination of glucocorticosteroids and mineralocorticosteroids in treating septic shock is not well-defined. The aim of this study was to perform a systematic review and meta-analysis of the randomized controlled trials and observational studies assessing the effect of low-dose hydrocortisone and fludrocortisone on patients with septic shock. Materials and Methods: MEDLINE, Scopus, and Cochrane databases were reviewed. A random effect model meta-analysis was used and $I$-square was used to assess the heterogeneity. Short-term mortality was chosen as our primary end point. A subgroup analysis was performed including only the randomized controlled trials. Results: A total of 10,550 patients were included in this meta-analysis. Administration of the steroid combination was associated with improved shortterm mortality (odds ratio, 0.78 , confidence interval, 0.64-0.96), intensive care unit mortality, and shock reversal, without increase in steroid-related side effects, such as secondary infection or gastrointestinal hemorrhage. Conclusion: This systematic review and meta-analysis showed that use of the combination of glucocorticosteroids and mineralocorticosteroids has a beneficial impact on short-term mortality, intensive care unit mortality, and shock reversal, without increasing the incidence of gastrointestinal hemorrhage or superinfection in patients with septic shock, when used as an adjunct treatment to the established standard of care.

Key words: Fludrocortisone, glucocorticosteroids, hydrocortisone, mineralocorticoids, septic shock, steroids

\section{INTRODUCTION}

Septic shock is characterized by a dysregulated host response to infection complicated by circulatory or cellular dysfunction ${ }^{[1]}$ and high short-term mortality. ${ }^{[2]}$ In addition to other measures, corticosteroids are suggested for septic shock management. ${ }^{[1]}$ Despite sound physiologic plausibility, extensive investigation into the efficacy of exogenous steroids have yielded variable outcomes. ${ }^{[3]}$

Address for correspondence: Dr. Leonidas Palaiodimos, Department of Medicine, Montefiore Medical Center, Albert Einstein College of Medicine, 111 East 210th Street, Bronx 10467, New York, USA.

E-mail: Leonidas.palaiodimos@gmail.com
Although most prior investigations have examined the impact of glucocorticosteroid supplementation alone, it remains unclear whether concomitant mineralocorticoid

This is an open access journal, and articles are distributed under the terms of the Creative Commons Attribution-NonCommercial-ShareAlike 4.0 License, which allows others to remix, tweak, and build upon the work non-commercially, as long as appropriate credit is given and the new creations are licensed under the identical terms.

For reprints contact: reprints@medknow.com

Cite this article as: Archontakis Barakakis P, Palaiodimos L, Fleitas Sosa D, Benes L, Gulani P, Fein D. Combination of low-dose glucocorticosteroids and mineralocorticoids as adjunct therapy for adult patients with septic shock: A systematic review and meta-analysis of randomized trials and observational studies. Avicenna J Med 2019;9:134-42. 
administration may be of additional benefit, as indicated by recent studies. ${ }^{[4-6]}$

We performed a systematic review and meta-analysis of the literature with the aim of further elucidating this matter.

\section{MATERIALS AND METHODS}

This systematic review and meta-analysis was performed according to the Preferred Reporting Items for Systematic Reviews and Meta-Analyses (PRISMA). MEDLINE, Scopus, and Cochrane databases were reviewed for potentially eligible randomized controlled trials (RCTs) and observational studies comparing the administration of glucocorticosteroids at a dose of 50-300 mg/day of hydrocortisone or equivalent in combination to fludrocortisone (steroid combination) as an adjunct treatment in septic shock versus placebo or no corticosteroids.

\section{Study selection and data extraction}

The algorithm used for the MEDLINE, Scopus, and Cochrane databases was as following: "(sepsis OR septic shock OR septicemia) AND (corticosteroids OR steroids)" with the necessary adjustments. The search was limited to human studies and adult population ( $>18$ years). No restrictions on language, publication date, or publication status were present. Two investigators (LB and DF) independently reviewed all retrieved references based on study title and abstract. Full texts were reviewed for all possibly relevant studies, and inclusion criteria were applied. A third independent investigator (LP) was involved as needed to reach consensus. To identify further eligible studies, manual searches of the references list of the included studies and pertinent reviews were performed.

Two independent reviewers (LB and DF) extracted data from the included studies using a predefined data collection form. Discrepancies were resolved with the involvement of a third reviewer (LP). Data for the following baseline variables were extracted: study name, first author, year of publication, duration of trial, population enrolled, number of participants enrolled, inclusion and exclusion criteria, definition of septic shock, mean age of participants, gender distribution of participants, severity of septic shock based on scoring tools available from studies (acute physiology, age, chronic health evaluation, Sequential Organ Failure Assessment [SOFA]), performance of a cosyntropin test, type, dose, route of administration, and duration of corticosteroids administered.

\section{Outcomes}

The primary efficacy end point was the all-cause mortality within 30 days. Mortality measured between 25 and 30 days following diagnosis of septic shock was considered equivalent. Secondary end points included intermediate-term mortality (31 days to six months following diagnosis of septic shock), longterm mortality (beyond six months from the diagnosis of septic shock), intensive care unit (ICU) mortality, in-hospital mortality, shock reversal within 30 days, vasopressor-free days, ventilatorfree days, duration of ICU admission, and incidence of serious adverse effects including hyperglycemia, gastrointestinal (GI) bleeding, delirium, and secondary infection.

\section{Risk of bias assessment}

Two independent reviewers (PAB and LB) assessed the risk of bias of the included studied using the Cochrane tool for randomized studies and the Robins-I tool for nonrandomized studies.

\section{Data synthesis and statistical analysis}

Definitions of the included outcomes were used as defined in the original studies. A random effects model was selected a priori because the included studies had heterogeneous study design and baseline patients' characteristics. ${ }^{[7]}$ Forest plots were used to illustrate the individual study findings and the random effects meta-analysis results. The $I$-square statistic $\left(I^{2}\right)$ was used to assess for heterogeneity among the studies. Dichotomous outcomes were calculated as odds ratios (ORs) with $95 \%$ confidence intervals (CIs) for the primary outcome and the secondary outcomes. For continuous outcomes, we calculated the mean differences with 95\% CIs. A 95\% CI not containing 1 for OR or a $P$ value $<0.05$ was considered as statistically significant. Statistical analysis was conducted with R (version 3.4.3) with RStudio (version 1.1.447 RStudio Inc., Boston, Massachusetts).

\section{RESULTS}

\section{Studies selection and characteristics}

In total, 1215 records were screened and 18 full-text articles were assessed for eligibility. Of these articles, only four studies, two RCTs, and two observational studies met the inclusion criteria and were included in the qualitative and quantitative analysis. ${ }^{[6,8-10]}$ The study selection process is presented with a PRISMA flow diagram [Figure 1]. The characteristics of the studies are summarized in Table 1.

In total, 10,550 patients were included. The greatest number of those (6747) came from one of the observational studies. ${ }^{[10]}$ The percentage of male patients was $68 \%$; however, the study that contributed most of the patients did not report their sex. ${ }^{[10]}$ Details on baseline patient characteristics are presented in Table 2. The included studies were deemed to present low risk of bias. The detailed assessment of risk of bias is presented in detail in Figure 2. 


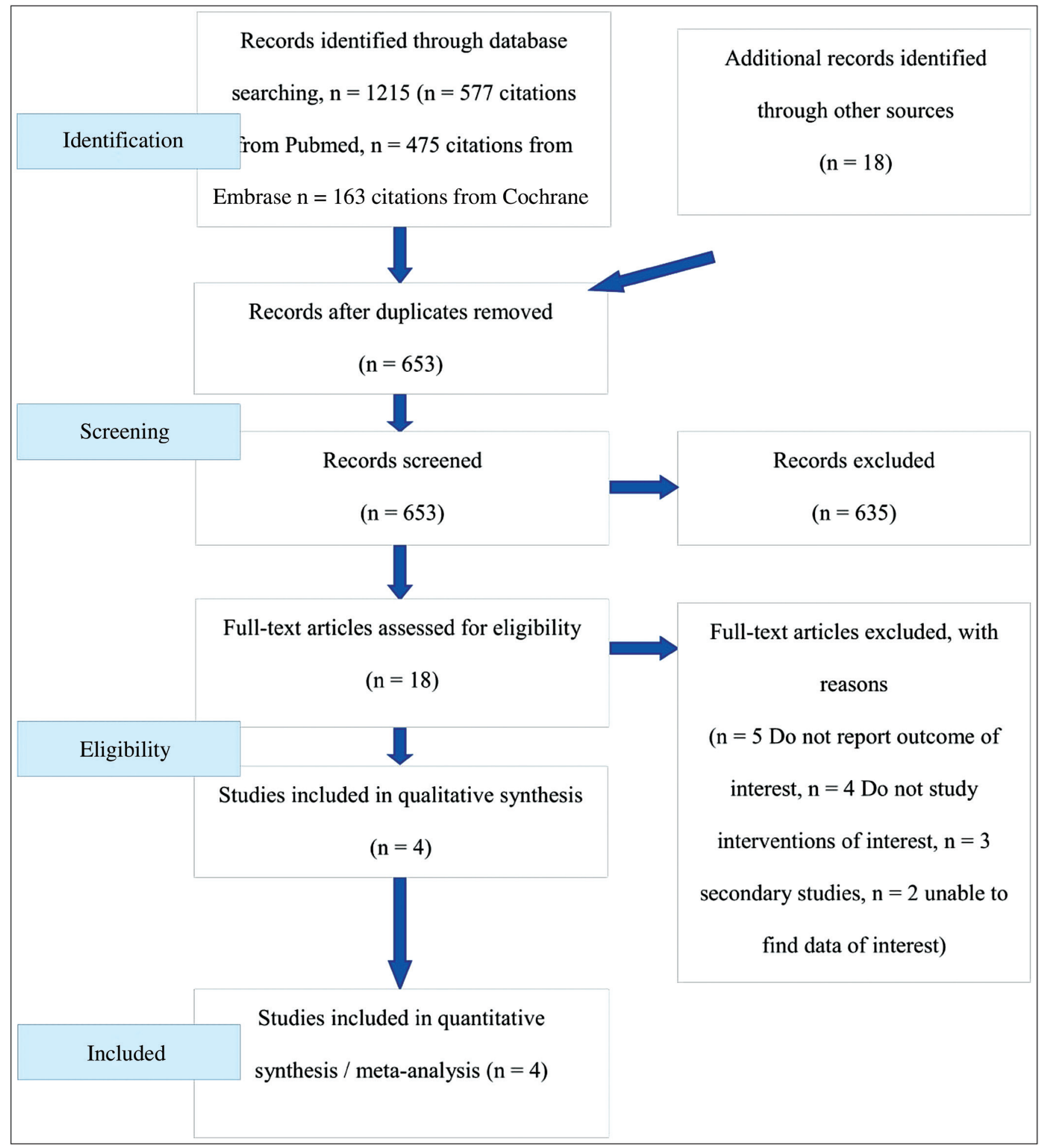

Figure 1: The Preferred Reporting Items for Systematic Reviews and Meta-Analyses (PRISMA) flowchart

\section{Primary outcome}

Data concerning the previously defined short-term mortality were available for a total of 1582 patients, collected from three studies (two RCTs and one observational). ${ }^{[6,8,9]}$ From those, 785 were included in the treatment arm and had a short-term mortality rate of 0.38 , whereas 797 patients were included in the placebo arm with a mortality rate of 0.43 .
Patients treated with the steroid combination were shown to have a lower short-term mortality (OR, 0.78 , CI, 0.64-0.96, $I^{2}=0.00 \%$; and $\left.P=0.0199\right)$ [Figure 3].

\section{Secondary outcomes}

The glucocorticoid and mineralocorticoid group had lower in-ICU mortality (OR, $\left.0.77, \mathrm{CI}, 0.63-0.95, I^{2}=0.00 \%\right)$, with 
Archontakis Barakakis, et al: The role of steroids in septic shock

\begin{tabular}{|c|c|c|c|c|c|c|c|}
\hline Study (year) & $\begin{array}{l}\text { Type of } \\
\text { study }\end{array}$ & $\mathbf{N}$ & $\begin{array}{c}\text { Shock } \\
\text { definition }\end{array}$ & Shock reversal & $\begin{array}{l}\text { Treatment } \\
\text { duration }\end{array}$ & $\begin{array}{c}\text { Glucocorticosteroid/ } \\
\text { dose }\end{array}$ & Mineralocorticoid/dose \\
\hline $\begin{array}{l}\text { Annane et al. }{ }^{[8]} \\
(2002)\end{array}$ & $\mathrm{RCT}$ & 299 & a & Pressor withdrawal & 7 days & $\begin{array}{l}\text { Hydrocortisone/Bolus } \\
\text { Intravenous, } 50 \mathrm{mg} \mathrm{q6} \mathrm{h}\end{array}$ & $\begin{array}{l}\text { Fludrocortisone/Bolus Per os, } \\
50 \mu g \text { every } 24 \text { hours }\end{array}$ \\
\hline $\begin{array}{l}\text { Annane et al. }{ }^{[6]} \\
(2018)\end{array}$ & RCT & $124 \mid$ & b & Pressor withdrawal & 7 days & $\begin{array}{l}\text { Hydrocortisone/Bolus IV, } \\
50 \mathrm{mg} \text { every } 6 \text { hours }\end{array}$ & $\begin{array}{l}\text { Fludrocortisone/Bolus PO, } 50 \mu \mathrm{g} \\
\text { every } 24 \text { hours }\end{array}$ \\
\hline $\begin{array}{l}\text { Bauer et al. }{ }^{[9]} \\
(2008)\end{array}$ & $\begin{array}{l}\text { Retrospective, } \\
\text { case-control }\end{array}$ & 42 & c & $\begin{array}{l}\text { Cessation of } \\
\text { vasopressors }>6 \mathrm{~h}\end{array}$ & $\begin{array}{l}5 \text { days } \\
\text { minimum }\end{array}$ & $\begin{array}{l}\text { Hydrocortisone/Bolus IV, } \\
50 \mathrm{mg} \text { every } 6 \text { hours }\end{array}$ & $\begin{array}{l}\text { Fludrocortisone/Bolus PO, } 50 \mu \mathrm{g} \\
\text { every } 24 \text { hours }\end{array}$ \\
\hline $\begin{array}{l}\text { Beale et al. }{ }^{[10]} \\
(2010)^{* *}\end{array}$ & $\begin{array}{l}\text { Retrospective } \\
\text { analysis of } \\
\text { PRPGRESS } \\
\text { database }\end{array}$ & 8968 & $\mathrm{D}$ & Not defined & Not defined & $\begin{array}{l}\text { Equivalent or } \\
\text { lesser potency to } \\
\text { hydrocortisone } 50 \mathrm{mg} / 6 \\
\text { hourly }\end{array}$ & $\begin{array}{l}\text { 9-alpha fludrocortisone/Bolus } \\
\text { PO, } 50 \mu \mathrm{g} \text { every } 24 \text { hours }\end{array}$ \\
\hline
\end{tabular}

$\mathrm{a}=(\mathrm{I})$ Systolic arterial pressure lower than $90 \mathrm{~mm} \mathrm{Hg}$ for at least I h despite adequate fluid replacement and more than $5 \mathrm{pg} / \mathrm{lcg}$ of body weight of dopamine or current treatment with epinephrine or norepinephrine, (2) urinary output of less than $0.5 \mathrm{~mL} / \mathrm{lcg}$ of body weight for at least I h or ratio of arterial oxygen tension to the fraction of inspired oxygen ( $\mathrm{PaO} 2 / \mathrm{FiO} 2)$ of less than $280 \mathrm{~mm} \mathrm{Hg}$, (3) arterial lactate levels higher than $2 \mathrm{mmol} / \mathrm{L}$, (4) need for mechanical ventilation, and (5) randomization within $3 \mathrm{~h}$ $b=(1)$ Sequential Organ Failure Assessment (SOFA) score of 3 or 4 for at least two organs and at least 6 h, (2) receipt of vasopressor therapy (norepinephrine, epinephrine, or any other vasopressor at a dose of $\geq 0.25 \mu \mathrm{g} / \mathrm{kg}$ of body weight per minute or $\geq 1 \mathrm{mg} / \mathrm{h}$ ) for at least $6 \mathrm{~h}$ to maintain a systolic blood pressure of at least $90 \mathrm{~mm} \mathrm{Hg}$ or a mean blood pressure of at least $65 \mathrm{~mm} \mathrm{Hg}$, (3) randomization within $24 \mathrm{~h}$ of septic shock onset

$c=(I)$ systolic blood pressure (SBP) not more than $90 \mathrm{~mm} \mathrm{Hg}$ or mean arterial pressure not more than $70 \mathrm{~mm} \mathrm{Hg} \mathrm{within} \mathrm{I} \mathrm{h} \mathrm{before} \mathrm{the} \mathrm{start} \mathrm{of} \mathrm{arginine} \mathrm{vasopressin} \mathrm{infusion,}$ (2) positive fluid balance, (3) mechanical ventilation, (4) at least two systemic inflammatory response syndrome (SIRS) criteria (one criterion in addition to mechanical ventilation), and (5) positive result in microbial culture or strong clinical suspicion of infection with the initiation of antimicrobials $d=$ No shock definition but presence of one or more acute organ dysfunctions

*Not reported, **We only included patients to whom vasopressors were administered

\begin{tabular}{|c|c|c|c|c|c|c|c|c|c|c|c|}
\hline & \multicolumn{2}{|c|}{$\begin{array}{l}\text { Annane et al. }{ }^{[8]} \\
(2002)\end{array}$} & \multicolumn{2}{|c|}{$\begin{array}{c}\text { Annane et al. }{ }^{[6]} \\
(2018)\end{array}$} & \multicolumn{2}{|c|}{$\begin{array}{l}\text { Bauer et al. }{ }^{[9]} \\
\quad(2008)\end{array}$} & \multicolumn{2}{|c|}{$\begin{array}{l}\text { Beale et al. }{ }^{[10]} \\
(2010)\end{array}$} & \multicolumn{3}{|c|}{ Meta-analysis } \\
\hline & Steroids & $\begin{array}{c}\text { No } \\
\text { steroids }\end{array}$ & Steroids & $\begin{array}{c}\text { No } \\
\text { steroids }\end{array}$ & Steroids & $\begin{array}{c}\text { No } \\
\text { steroids }\end{array}$ & Steroids & $\begin{array}{c}\text { No } \\
\text { steroids }\end{array}$ & Steroids & $\begin{array}{c}\text { No } \\
\text { steroids }\end{array}$ & Total \\
\hline N & 150 & 149 & 614 & 627 & 21 & 21 & $3,05 I$ & 5,917 & 3,836 & $6,7 \mid 4$ & 10,550 \\
\hline Age & 62 & 60 & 66 & 66 & 63.5 & 67.7 & 62.4 & 59.5 & 62.97 & 60.14 & 61.17 \\
\hline Male & 96 & 104 & 424 & 427 & 12 & II & & & 532 & 542 & $\mathrm{I}, 074$ \\
\hline SAPS $\|^{a}$ & 60 & 57 & 56 & 56 & 56.8 & 59.2 & & & 56.79 & 56.27 & 56.53 \\
\hline APACHE $\|^{b, c}$ & & & & & 27.1 & 27.7 & 24.7 & 22.1 & 24.72 & 22.12 & 23.01 \\
\hline SOFA $^{c}$ & & & 12 & II & II & 10.1 & 10.1 & 8.6 & 10.43 & 8.83 & 9.40 \\
\hline $\begin{array}{l}\text { Positive culture/documented } \\
\text { pathogen }^{\mathrm{a}}\end{array}$ & 121 & 126 & 450 & $44 I$ & 14 & 10 & & & 585 & 577 & 1162 \\
\hline Epinephrine ${ }^{\mathrm{a}}$ & 41 & 31 & 53 & 58 & 1 & 3 & & & 95 & 92 & 187 \\
\hline Norepinephrine ${ }^{a}$ & 46 & 48 & 534 & 552 & 10 & 9 & & & 590 & 609 & 1,199 \\
\hline Dopamine $e^{\mathrm{a}, \mathrm{b}}$ & 136 & 137 & & & 4 & 4 & & & 140 & $|4|$ & 281 \\
\hline Dobutamine $e^{\mathrm{a}, \mathrm{b}, \mathrm{d}}$ & 53 & 51 & & & & & & & 53 & 51 & 104 \\
\hline Phenylephrine $e^{a, b, c}$ & & & & & 8 & 1 & & & 8 & 1 & 9 \\
\hline Vasopressor ${ }^{b, c, d}$ & & & & & & & 2,794 & 4,366 & & & \\
\hline Mechanical ventilation & 150 & 149 & 567 & 569 & 21 & 21 & 2,801 & 4,743 & 3,539 & 5,482 & 9,021 \\
\hline Renal replacement therapyc & & & 161 & 168 & 8 & 1 & 895 & 981 & 1,064 & 1,150 & 2,214 \\
\hline
\end{tabular}

patient data available from three studies (two RCTs and one observational $),{ }^{[6,8,9]}$ and improved shock reversal rate within 30 days (OR, 0.69, CI, 0.54-0.89, $I^{2}=0.00 \%$ ), with patient data available from two RCTs. ${ }^{[6,8]}$ No significant difference was observed between the two groups regarding the hospital mortality (OR, 0.93, CI, 0.55-1.58, $I^{2}=92.30 \%$ ), data available from all included studies ${ }^{[6,8-10]}$ GI hemorrhage (OR, 1.05, CI, 0.77-1.42, $I^{2}=0.00 \%$ ), with patient data available from two RCTs, ${ }^{[6,8]}$ or superinfection (OR, 0.95 , CI, $0.64-1.42, I^{2}=21.38 \%$ ), with patient data available from two RCTs ${ }^{[6,8]}$ [Figures 4-8]. No data were available to pool in more than one study concerning the rest of the investigated outcomes, namely intermediate-term, long-term mortality, vasopressor-free days, ventilator-free days, duration of
ICU admission, and incidence of serious adverse effects, including hyperglycemia and delirium.

\section{Meta-analysis of the RCTs only}

A separate analysis of the RCTs was performed. ${ }^{[6,8]}$ The patients in the steroids arm showed lower short-term mortality (OR, 0.79 , CI, 0.64-0.97, $I^{2}=0.00 \%$ ), decreased in-ICU mortality (OR, 0.77, CI, 0.63-0.95, $I^{2}=0.00 \%$ ), and decreased in-hospital mortality (OR, 0.77, CI, 0.63-0.95, $I^{2}=0.00 \%$ ) [Figures 9-11].

\section{DISCUSSION}

This systematic review and meta-analysis was performed to investigate the simultaneous use of low-dose 


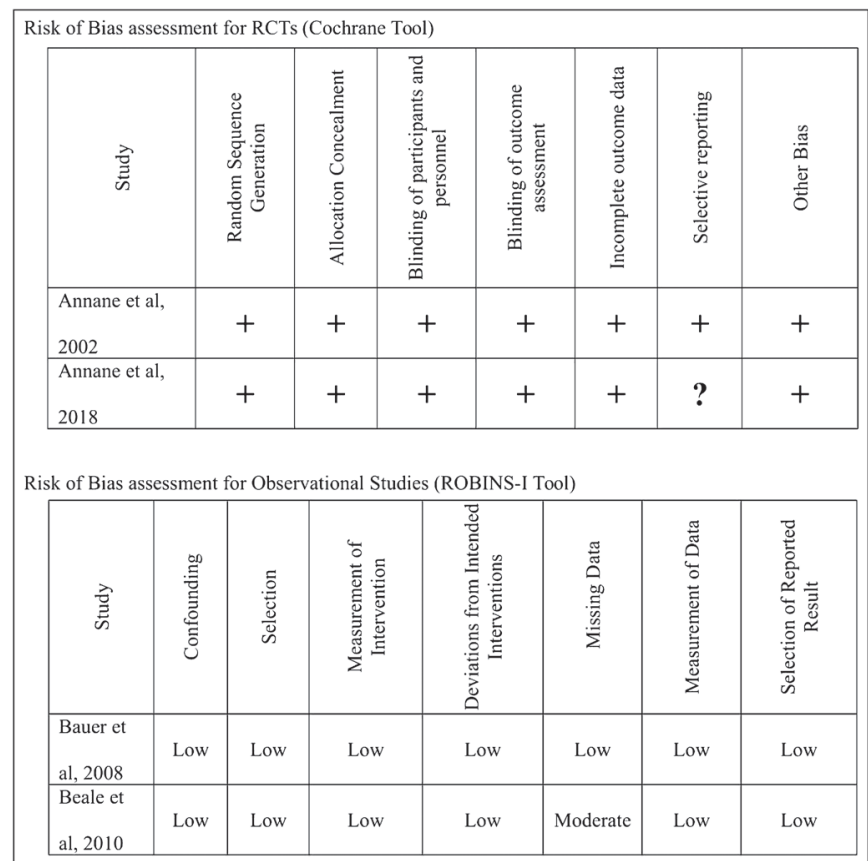

Figure 2: The risk of bias assessment

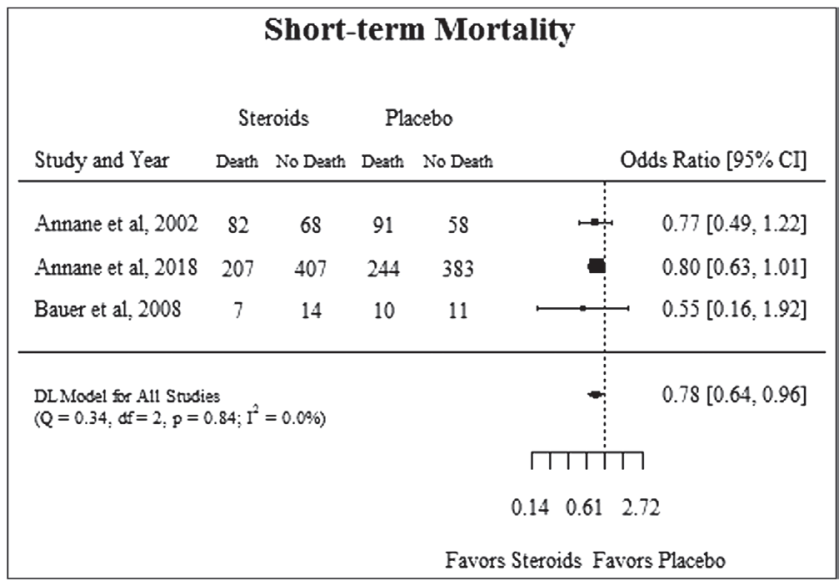

Figure 3: Effect of corticosteroids versus placebo on short-term mortality

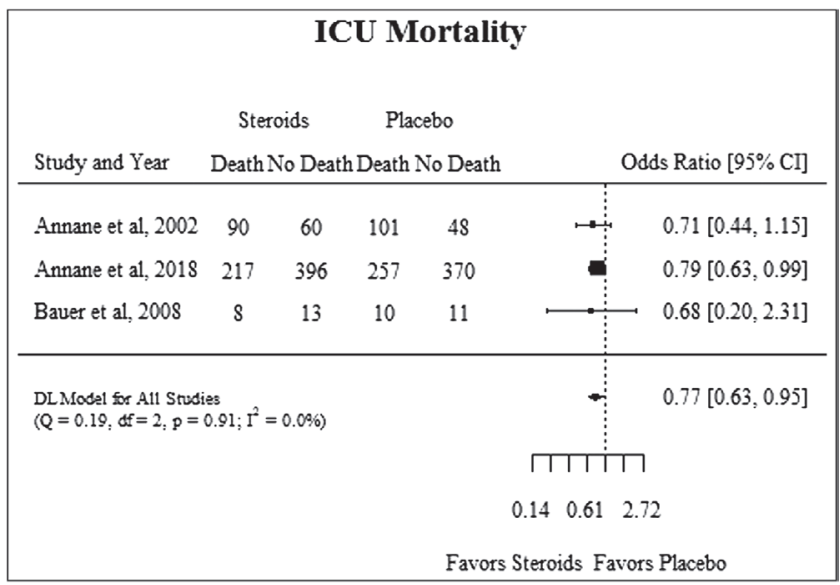

Figure 4: Effect of corticosteroids versus placebo on intensive care unit mortality

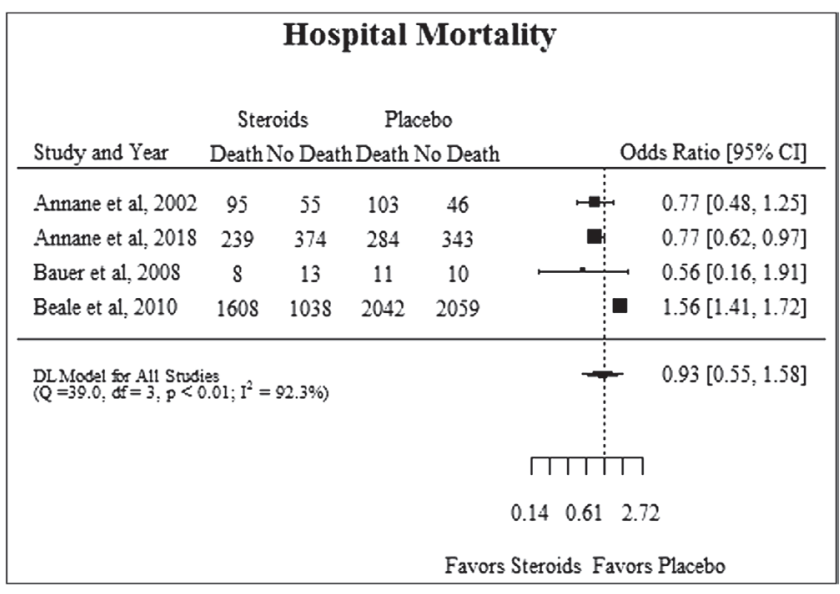

Figure 5: Effect of corticosteroids versus placebo on hospital mortality

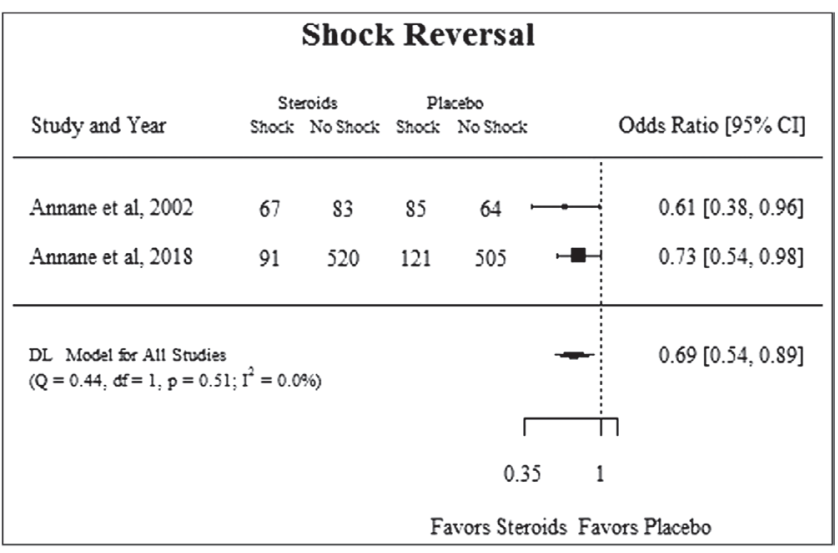

Figure 6: Effect of corticosteroids versus placebo on shock reversal

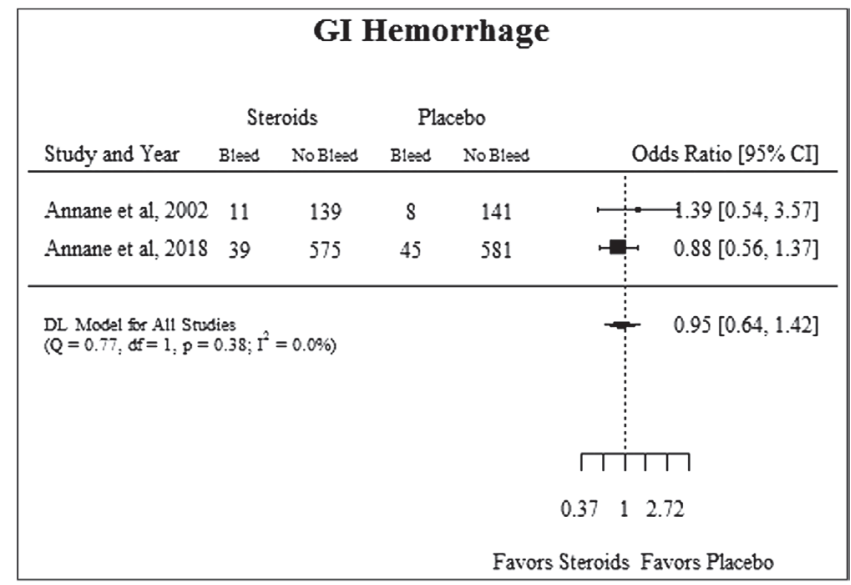

Figure 7: Effect of corticosteroids versus placebo on gastrointestinal hemorrhage

glucocorticosteroids and mineralocorticosteroids as an adjunct treatment in the management of septic shock. We showed that the steroid combination, including mineralocorticosteroids, decreased the short-term mortality of patients with septic shock. We additionally found that patients receiving both glucocorticosteroids 


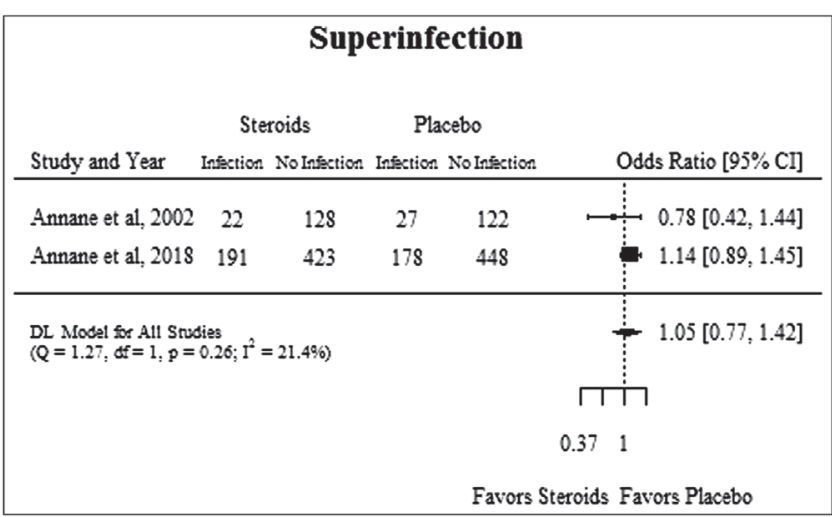

Figure 8: Effect of corticosteroids versus placebo on superinfection

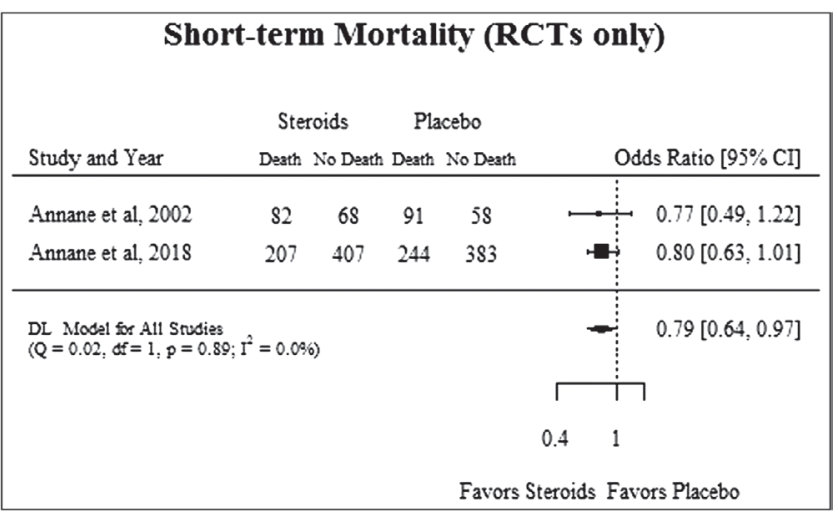

Figure 9: Effect of corticosteroids versus placebo on short-term mortality (randomized trials only)

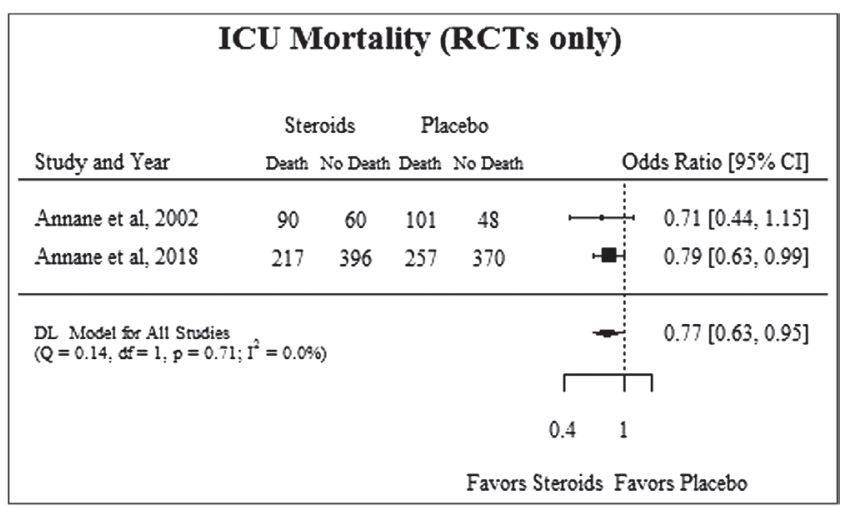

Figure 10: Effect of corticosteroids versus placebo on intensive care unit mortality (randomized trials only)

and mineralocorticosteroids had lower ICU mortality and improved shock reversal rate within 30 days. We found no increased rate of serious adverse events associated with the administration of these therapies including incidence of GI hemorrhage or superinfection. No impact on inhospital mortality was noted with the inclusion of all studies, although improvement was discovered when the metaanalysis pooled data only from the RCTs.

The question of using corticosteroids within the realm of sepsis and septic shock has been attempted to be answered

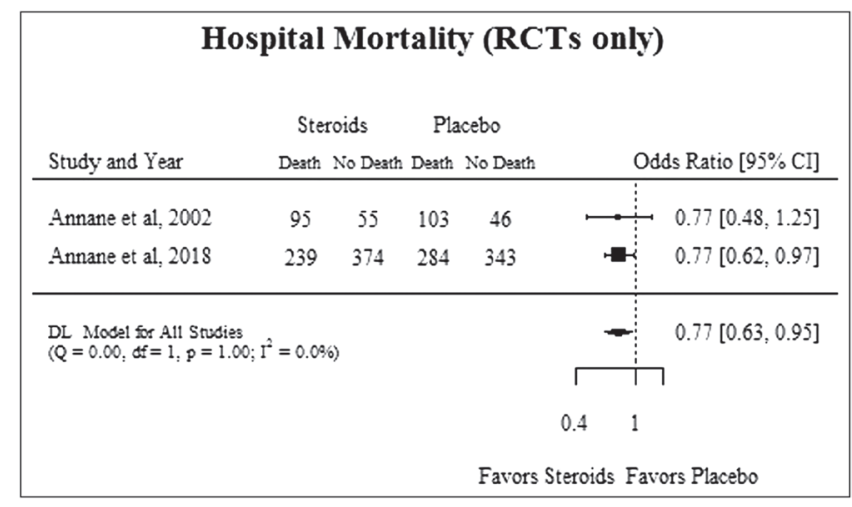

Figure 11: Effect of corticosteroids versus placebo on hospital mortality (randomized trials only)

over a number of years. There has been a constant interest on the subject that resulted in primary research studies as well as meta-analyses assessing the utility of glucocorticosteroids. ${ }^{[11]}$ We chose to focus on the concurrent use of both types of corticosteroids because of the increasing volume of evidence that mineralocorticosteroids can be beneficial to the management of sepsis and septic shock. Although multiple prior meta-analyses have been performed to examine the impact of steroids for adjunctive treatment of septic shock, to the best of our knowledge, this is the first investigation to focus on the use of mineralocorticoids along with glucocorticoids.

Despite an element of discrepancy among the studies, including differences in their choice of primary outcome and more importantly their definition of septic shock, we chose the short-term mortality as our primary outcome, as it was thought to be the most clinically relevant. All included studies showed mortality benefit but with mixed levels of statistical significance. Our pooled result agreed with the aforementioned trend with the added bonus of increased power. Despite its innate limitations as a mortality measure, ICU mortality was also found to be very similarly decreased among the treatment group.

The rational of administering glucocorticosteroids in the setting of septic shock mainly focuses on reversing the multilevel dysfunction that it causes to the hypothalamuspituitary-adrenal-tissue axis. There are several parallel functioning mechanisms that would contribute to this phenomenon, the analysis of which falls outside the scope of this study. ${ }^{[12-15]}$ However, incorporating all these knowledge into clinical practice has been challenging, at least partially because there is no consensus concerning the optimal method of assessing the axis in sepsis conditions. ${ }^{[16]}$ As such, the effect of glucocorticosteroid administration on hemodynamic status and cellular function of administering glucocorticosteroids in sepsis conditions has been investigated directly with human and animal models. ${ }^{[17]}$ 
The mechanisms and the effects of mineralocorticosteroids are similar to the ones associated with glucocorticosteroids. First of all, their action is performed via cytoplasmic receptors that alter protein synthesis on activation, ${ }^{[17,18]}$ but also via non-genomic and more rapid in onset mechanisms involving plasma membrane receptor activation. The nature and exact function of this latter mechanism has recently been better investigated and not only does it provoke a vasoactive effect during sepsis but also this effect is entirely independent of glucocorticosteroids. ${ }^{[18,19]}$ The perceived clinical manifestation of the action of those mechanisms is the restoration of alpha-1 adrenergic activity with subsequent improvement of the measured blood pressure in not only animal but also human models. ${ }^{[20]}$

The combined effect and interaction of glucocorticosteroids and mineralocorticosteroids is less than well-understood and complex on several levels. First, the action of both types of steroids is mediated at least partially independently, as detailed earlier. Second, despite the fact that both natural steroids have equal affinity of the glucocorticoid receptor, ${ }^{[21]}$ the glucocorticosteroid analog, hydrocortisone, and the mineralocorticosteroid analog, fludrocortisone, used in most experimental series, show significant potency difference in activating this receptor. ${ }^{[22]}$ Third, it is indeed documented that the enzyme responsible for the intracellular metabolism of corticosteroids in the aldosterone sensitive tissues, $11 \beta$-hydroxysteroid dehydrogenase type 2 , is saturated by the daily dose of $200 \mathrm{mg}$ of hydrocortisone alone, ${ }^{[17,23]}$ and as such it could be argued that the activation of the mineralocorticosteroid receptor (MR) could be solely performed by the remaining hydrocortisone without the need for fludrocortisone. However, this statement might be misleading, as protein synthesis provoked by the binding of a ligand to the receptor is further regulated by a significant variety of additional factors, mainly coactivator and corepressor proteins. ${ }^{[24]}$ The function of a number of these molecules depends on the nuclear redox state, essentially functioning as a redox status sensing mechanism. ${ }^{[25]}$ The activation of $11 \beta$-hydroxysteroid dehydrogenase type 2 directly results in intracellular redox status changes via the metabolism of nicotinamide adenine dinucleotide $(\mathrm{NAD}+) / \mathrm{NADH} \cdot{ }^{[26]}$ In short, the MR-ligand binding could very well produce different results with regard to protein synthesis, with glucocorticosteroids functioning either as an activator or an inhibitor depending on the redox state of the tissue. As expected, this effect cannot be accurately predicted during septic shock, especially in the endothelial as well as other blood vessel cells. ${ }^{[17,24]}$ Although difficult to exhaust the physiology behind their interaction, the net effect of the simultaneous use of glucocorticosteroids and mineralocorticosteroids seems to be the achievement of improved blood pressure control, decreased pressor requirements in healthy and septic conditions in human and animal models. ${ }^{[4,5]}$

The aforementioned mechanisms could explain the discrepancy of the results between the adjunctive corticosteroid treatment in critically ill patients with septic shock and activated protein $\mathrm{C}$ and corticosteroids for human septic shock trials, ${ }^{[6,27]}$ especially with regard to their primary outcome, with the first failing and the latter succeeding in showing statistically significant 90 -day mortality benefit between the treatment and placebo groups. Other factors might have attributed to this discrepancy as well. First, there were methodological differences between the two trials, with the ADRENAL trial using an infusion of hydrocortisone instead of bolus doses used in APROCCHSS trial, thus achieving therapeutic levels later, and second, allowing longer time to randomization than APROCCHSS trial. These differences may have caused adequate temporal delay to miss a potentially reversible stage of shock in the ADRENAL trial. Finally, the baseline characteristics of the patients included in the two trials were deemed unequal, especially concerning the severity of the shock.

At this point, it is important to mention findings of the Corticosteroids and Intensive Insulin Therapy for Septic Shock (COIITSS) trial. ${ }^{[28]}$ In a study designed to assess the effect of tight glycemic control versus regular practice control as well as the effect of the combination of glucocorticosteroid and mineralocorticosteroid versus the sole use of glucocorticosteroids, no difference in the measured variables was revealed. Despite this result, it is thought that the effort to answer both questions might have compromised its ability to tackle either of them. Furthermore, the research team that conducted the study has suggested that it might have been underpowered to demonstrate the difference between the two treatments.

Regarding our secondary end points, we are unable to reach a safe conclusion concerning hospital mortality. Although not entirely clear, the aforementioned discrepancy could partially be attributed to a difference in the definitions of shock (including the significant detail of inclusion of patients before or after a level of initial fluid resuscitation), the definition of resolution of shock, the specific definition of said measures in its study, and the difference in practice among the study centers. A characteristic example for the latter would be the frequency and speed of the decision to de-escalate terminal patients from ICU, directly altering not only ICU but hospital mortality as well. Especially concerning the assessment of the rate of shock resolution, the documented measures differed between vasopressor- 
free days and vasopressor use duration, making statistical analysis difficult without access to patient-level data. Finally, intermediate and long-term mortality were indeed assessed as secondary end points but the paucity of data for these end points was observed in the form of lack of well-aligned, more long-term (e.g., 90, 180 days, or 1 year) mortality reporting between the studies.

To the best of our knowledge, this was the first systematic review and meta-analysis dedicated to the study of the effect of both steroids as an adjunct therapy to the septic shock treatment. Our methodology adhered to PRISMA guidelines and our search included all the major databases. The quality of the included studies was assessed for biases with the appropriate assessment tools. Finally, the heterogeneity of the included studies was low.

Our study did have certain limitations. First, the number of studies that met our criteria was small. The clinical question of steroid use in sepsis had been debated over a number of decades with no conclusive answer. Despite the relatively large number of studies using glucocorticosteroids for the management of sepsis, a far smaller number combined them with mineralocorticosteroids. As a result of the aforementioned, it was deemed necessary to include observational studies. However, the results were not substantially altered by the inclusion of the observational studies, even though the main contribution to in-hospital mortality patient numbers belonged to one observational study. Finally, one of the major questions, rate of shock resolution, was left unanswered because of the different methods of assessing this variable. Studies tend to use and publish either the duration of shock or pressor-free days, measures that are not interchangeable, as explained earlier.

In conclusion, our systematic review and meta-analysis concluded that coadministration of glucocorticosteroids and mineralocorticosteroids to patients with septic shock results in decreased short-term mortality, decreases ICU mortality, and increases incidence of shock resolution in 30 days compared to placebo. No definitive effect was appreciated on hospital mortality as well as on the incidence of undesired effects, specifically development of superinfection and GI hemorrhage. Although future investigation into the role of adjunctive mineralocorticoids in septic shock is needed, our analysis suggests that clinicians may have a sound basis to administer these agents along with glucocorticosteroids to patients with septic shock.

\section{Financial support and sponsorship}

Nil.

\section{Conflicts of interest}

There are no conflicts of interest.

\section{REFERENCES}

1. Rhodes A, Evans LE, Alhazzani W, Levy MM, Antonelli M, Ferrer R, et al. Surviving sepsis campaign: International guidelines for management of sepsis and septic shock: 2016. Intensive Care Med 2017;43:304-77.

2. Angus DC, Linde-Zwirble WT, Lidicker J, Clermont G, Carcillo J, Pinsky MR. Epidemiology of severe sepsis in the United States: Analysis of incidence, outcome, and associated costs of care. Crit Care Med 2001;29:1303-10.

3. Bruno JJ, Dee BM, Anderegg BA, Hernandez M, Pravinkumar SE. US practitioner opinions and prescribing practices regarding corticosteroid therapy for severe sepsis and septic shock. J Crit Care 2012;27:351-61.

4. Laviolle B, Donal E, Le Maguet P, Lainé F, Bellissant E. Low doses of fludrocortisone and hydrocortisone, alone or in combination, on vascular responsiveness to phenylephrine in healthy volunteers. $\mathrm{Br} \mathrm{J}$ Clin Pharmacol 2013;75:423-30.

5. Laviolle B, Nesseler N, Massart C, Bellissant E. Fludrocortisone and hydrocortisone, alone or in combination, on in vivo hemodynamics and in vitro vascular reactivity in normal and endotoxemic rats: A randomized factorial design study. J Cardiovasc Pharmacol 2014;63:488-96.

6. Annane D, Renault A, Brun-Buisson C, Megarbane B, Quenot JP, Siami S, et al. Hydrocortisone plus fludrocortisone for adults with septic shock. N Engl J Med 2018;378:809-18.

7. Riley RD, Higgins JP, Deeks JJ. Interpretation of random effects metaanalyses. BMJ 2011;342:d549.

8. Annane D, Sébille V, Charpentier C, Bollaert PE, François B, Korach JM, et al. Effect of treatment with low doses of hydrocortisone and fludrocortisone on mortality in patients with septic shock. JAMA 2002;288:862-71.

9. Bauer SR, Lam SW, Cha SS, Oyen LJ. Effect of corticosteroids on arginine vasopressin-containing vasopressor therapy for septic shock: A case control study. J Crit Care 2008;23:500-6.

10. Beale R, Janes JM, Brunkhorst FM, Dobb G, Levy MM, Martin GS, et al. Global utilization of low-dose corticosteroids in severe sepsis and septic shock: A report from the PROGRESS registry. Crit Care 2010;14:R102.

11. Rygård SL, Butler E, Granholm A, Møller MH, Cohen J, Finfer S, et al. Lowdose corticosteroids for adult patients with septic shock: A systematic review with meta-analysis and trial sequential analysis. Intensive Care Med 2018;44:1003-16.

12. Sharshar T, Gray F, Lorin de la Grandmaison G, Hopkinson NS, Ross E, Dorandeu A, et al. Apoptosis of neurons in cardiovascular autonomic centres triggered by inducible nitric oxide synthase after death from septic shock. Lancet 2003;362:1799-805.

13. Polito A, Sonneville R, Guidoux C, Barrett L, Viltart O, Mattot V, et al. Changes in $\mathrm{CRH}$ and ACTH synthesis during experimental and human septic shock. PLoS One 2011;6:e25905.

14. Annane D, Maxime V, Ibrahim F, Alvarez JC, Abe E, Boudou P. Diagnosis of adrenal insufficiency in severe sepsis and septic shock. Am J Respir Crit Care Med 2006;174:1319-26.

15. Polito A, Lorin de la Grandmaison G, Mansart A, Louiset E, Lefebvre H, Sharshar $\mathrm{T}$, et al. Human and experimental septic shock are characterized by depletion of lipid droplets in the adrenals. Intensive Care Med 2010;36:1852-8.

16. Annane D, Pastores SM, Rochwerg B, Arlt W, Balk RA, Beishuizen A, et al. Guidelines for the diagnosis and management of critical illnessrelated corticosteroid insufficiency (CIRCI) in critically ill patients (part I): Society of Critical Care Medicine (SCCM) and European 
Society of Intensive Care Medicine (ESICM) 2017. Intensive Care Med 2017;43:1751-63.

17. Funder JW. Aldosterone and mineralocorticoid receptors—Physiology and pathophysiology. Int J Mol Sci 2017;18:1032.

18. Grossmann C, Benesic A, Krug AW, Freudinger R, Mildenberger S, Gassner B, et al. Human mineralocorticoid receptor expression renders cells responsive for nongenotropic aldosterone actions. Mol Endocrinol 2005;19:1697-710.

19. Wildling L, Hinterdorfer P, Kusche-Vihrog K, Treffner Y, Oberleithner H. Aldosterone receptor sites on plasma membrane of human vascular endothelium detected by a mechanical nanosensor. Pflugers Arch 2009;458:223-30.

20. Fadel F, André-Grégoire G, Gravez B, Bauvois B, Bouchet S, Sierra-Ramos C, et al. Aldosterone and vascular mineralocorticoid receptors in murine endotoxic and human septic shock. Crit Care Med 2017;45:e954-62.

21. Arriza JL, Weinberger C, Cerelli G, Glaser TM, Handelin BL, Housman DE, et al. Cloning of human mineralocorticoid receptor complementary DNA: Structural and functional kinship with the glucocorticoid receptor. Science 1987;237:268-75.

22. Druce LA, Thorpe CM, Wilton A. Mineralocorticoid effects due to cortisol inactivation overload explain the beneficial use of hydrocortisone in septic shock. Med Hypotheses 2008;70: 56-60.

23. Funder JW. Apparent mineralocorticoid excess. J Steroid Biochem Mol Biol 2017;165:151-3.

24. Gomez-Sanchez E, Gomez-Sanchez CE. The multifaceted mineralocorticoid receptor. Compr Physiol 2014;4:965-94.

25. Fjeld CC, Birdsong WT, Goodman RH. Differential binding of NAD+ and NADH allows the transcriptional corepressor carboxyl-terminal binding protein to serve as a metabolic sensor. Proc Natl Acad Sci U S A 2003;100:9202-7.

26. Zhou MY, Gomez-Sanchez EP, Cox DL, Cosby D, Gomez-Sanchez CE. Cloning, expression, and tissue distribution of the rat nicotinamide adenine dinucleotide-dependent 11 beta-hydroxysteroid dehydrogenase. Endocrinology 1995;136:3729-34.

27. Venkatesh B, Finfer S, Cohen J, Rajbhandari D, Arabi Y, Bellomo R, et al. Adjunctive glucocorticoid therapy in patients with septic shock. N Engl J Med 2018;378:797-808.

28. Annane D, Cariou A, Maxime V, Azoulay E, D'honneur G, Timsit JF, et al. Corticosteroid treatment and intensive insulin therapy for septic shock in adults: A randomized controlled trial. JAMA 2010;303: 341-8. 